\title{
APLICAÇÃo CONJUNTA de TRATAMENTO ANAERÓBIO TERMOFÍLICO POR LODO GRANULAR E DE MEDIADORES REDOX NA REMOÇÃO DE COR DE ÁGUAS RESIDUÁRIAS TÊXTEIS
}

\author{
APPLICABILITY OF BOTH THERMOPHILIC TREATMENT BY ANAEROBIC \\ GRANULAR SLUDGE AND REDOX MEDIATORS ON COLOUR \\ REMOVAL OF TEXTILE WASTEWATERS
}

\begin{abstract}
ANDRE BEZERRA DOS SANTOS
Doutor em Saneamento Ambiental pela Universidade de Wageningen (WUR), Wageningen, Holanda. Pesquisador DCR da Fundação Cearense de Amparo à Pesquisa (FUNCAP) junto ao Departamento de Engenharia Hidráulica e Ambiental (DEHA) da Universidade Federal do Ceará (UFC)

Recebido: 01/09/04 Aceito: 03/08/05
\end{abstract}

\section{RESUMO}

Investigou-se o efeito de diferentes mediadores redox na remoção de cor de corantes azo pelo uso de lodo granular anaeróbio sob condições mesofílicas $\left(30^{\circ} \mathrm{C}\right)$ e termofílicas $\left(55^{\circ} \mathrm{C}\right)$. Adicionalmente, estudou-se em ambas temperaturas, o efeito de diferentes doadores de elétrons nos processos de descoloração. Comprovou-se em tais processos um impacto marcante da adição de concentrações catalíticas de mediadores redox, aumentando a cinética da reação em até 1 ordem de magnitude. Comparado com tratamento mesofílico, remoçōes de cor sob condiçōes termofílicas foram extremamente aceleradas, além de o impacto dos mediadores redox ser consideravelmente diminuído à $55^{\circ} \mathrm{C}$. Por exemplo, em experimento de fluxo contínuo, eficiências de remoção em torno de $95 \%$ e $56 \%$ foram obtidas à $55^{\circ} \mathrm{C} \mathrm{e} 30^{\circ} \mathrm{C}$, respectivamente, na ausência de qualquer mediador redox. Hidrogênio se mostrou extremamente efetivo como doador de elétrons para o processo de descoloração redutiva de corantes azo quando comparado com glicose, formiato e acetato. Os resultados obtidos nesta investigação trazem boas perspectivas para o uso conjunto de reatores anaeróbios sob condições termofílicas e de mediadores redox no pré-tratamento das águas residuárias de indústrias têxteis.

PALAVRAS-CHAVE: Remoção de cor; corantes azo; tratamento anaeróbio; mediadores redox; tratamento mesofilico e termofílico.

\begin{abstract}
The use of different redox mediators on colour removal of azo dyes by anaerobic granular sludge was investigated under mesophilic $\left(30^{\circ} \mathrm{C}\right)$ and thermophilic $\left(55^{\circ} \mathrm{C}\right)$ conditions. Additionally, the use of different electron donors on the reductive decolourisation was studied in both temperatures. The addition of catalytic concentrations of redox mediators had an evident impact on the decolourisation process, enhancing the rates up to one order of magnitude. Compared to mesophilic conditions, colour removal under thermophilic conditions was extremely accelerated, and the impact of redox mediators on the decolourisation rates was considerably decreased at $55^{\circ} \mathrm{C}$. For instance, in a continuous flow experiment, efficiencies of around $95 \%$ and $56 \%$ were obtained at $55^{\circ} \mathrm{C}$ and $30^{\circ} \mathrm{C}$, respectively, in the absence of redox mediators. Hydrogen was a much better electron donor for sustaining dye reduction than glucose, formate and acetate. The present results bring good prospects for the use of thermophilic anaerobic treatment and redox mediators on colour removal of textile wastewaters.
\end{abstract}

KEYWORDS: Colour removal; azo dyes; anaerobic treatment; redox mediators; mesophilic and thermophilic treatment.

\section{INTRODUÇÃO}

A indústria têxtil representa um importante setor da economia brasileira e mundial, tendo experimentado considerável crescimento nos últimos anos. Como conseqüência, essa indústria tem aumentado a produção de esgotos, sendo um potencial contribuinte à degradação do meio-ambiente. Uma das principais características desses efluentes é que os mesmos são altamente coloridos, resultado principalmente dos corantes que são apli- cados nas operações de tingimento. É estimado que $10^{9} \mathrm{~kg}$ de corantes são anualmente produzidos no mundo, dos quais $70 \%$ pertencem à classe dos corantes azo (-N-N-) (Zollinger, 1987). Juntamente com estes, outros corantes como os antraquinônicos (contém quinonas na sua estrutura) e ftalocianinos (contém metais) são amplamente utilizados (Christie, 2001). O lançamento em corpos de água de efluentes contendo altas concentraçôes de corantes é indesejável pois os mesmos podem afetar a fotossíntese das algas, além do fato de muitos desses corantes e seus produtos de degradação serem carcinogênicos (Weisburger, 2002). Processos de remoção de cor de efluentes têxteis têm sido um constante desafio para a ciência nas últimas décadas, e até o presente não há um único e econômico tipo de tratamento que seja efetivamente capaz de ser empregado nas estações de tratamento de esgotos. Entretanto nos últimos anos, grandes progressos foram alcançados na área de biotecnologia ambiental aplicada à descoloração de 
corantes, no qual diferentes microrganismos à citar bactérias aeróbias e anaeróbias, fungos e actinomicetos se mostraram possuir tais propriedades (Dos Santos, 2005). O mecanismo de ação entre tais microrganismos é bem variado, envolvendo tanto mecanismos oxidativos como redutivos. Por exemplo, bactérias aeróbias somente removem cor quando possuem enzimas chamadas azo redutases, as quais são catalisadas na presença de oxigênio (Stolz, 2001). Tais enzimas foram descobertas em organismos do tipo Pseudomonas K22 e KF46, e Pagmentiphaga kullae K24 (Zimmermann et al, 1982; Blumel e Stolz, 2003). Já a capacidade de fungos em remover cor é associada com a formação de exo-enzimas tais quais peroxidases e fenolxidases, e conseqüente oxidação dos corantes (Duran et al, 2002). Espécies fúngicas do tipo Bjerkandera adusta, Trametes versicolor e Phanerochaete chrysosporium mostraram ser eficientes na oxidação de corantes (Heinfling et al, 1997).

A remoção de cor de corantes azo por bactérias aeróbias, a citar nos sistemas de lodos ativados, é normalmente baixa (10-30\%), a qual é associada principalmente a adsorção do corante no lodo ativo (Dos Santos, 2005). Isso se dá em decorrência da preferência do aceptor final de elétrons, oxigênio, comparada aos corantes azo, pelos elétrons gerados nos processos oxidativos (produção de ATP) (Stolz, 2001). Por outro lado sob condiçôes anaeróbias, tais corantes são usualmente os únicos aceptores finais de elétrons, fazendo com que melhores eficiências de remoção sejam alcançadas (60$80 \%$ ). Entretanto, durante esse processo redutivo os corantes azo dão origem às incolores (usualmente) aminas aromáticas, as quais são recalcitrantes sob condições anaeróbias. Assim antes de qualquer emissão, pós-tratamentos devem ser incluídos de forma a remover as aminas aromáticas, pelo fato de as mesmas serem carcinogênicas (Dos Santos, 2005).
Foi recentemente descoberto que a aplicação conjunta do tratamento anaeróbio com mediadores redox aumentava a cinética de redução de corantes azo em até 1 ordem de magnitude, na qual os mediadores redox aceleravam a taxa de transferência de elétrons do doador primário ao receptor final de elétrons. Tal transferência de elétrons é usualmente o limitante do processo de redução (Lovley et al, 1996; Dos Santos et al, 2005). Vitaminas como riboflavina (Vitamina B2), e outras substâncias como as quinonas presentes em húmus e carvão ativado, podem funcionar como mediadores redox (Rau et al, 2002; Dos Santos et al, 2004). A remoção de cor na presença dessas substâncias se dá em duas fases: a primeira fase consiste na redução enzimática do mediador redox através dos elétrons gerados nos processos oxidativos; e a segunda fase consiste na transferência química desses elétrons para os corantes azo, com a conseqüente regeneração dos mediadores redox (Figura 1) (Keck et al, 1997).

Até o presente, a aplicação conjunta de mediadores redox e lodo granular anaeróbio, nos processos de redução de corantes azo, foi somente estudada sob condições mesofílicas (Van Der Zee et al, 2001; Cervantes et al, 2001). Entretanto, constatou-se que efeito nas taxas de descoloração devido à mudança de operação do reator de condições mesofílicas para condições termofílicas era muitas vezes maior do que o próprio efeito dos mediadores redox (Dos Santos et al, 2003; Dos Santos et al, 2005). Isso somado ao fato de que as águas residuárias têxteis são normalmente descartadas sob altas temperatures, traz boa perspectiva à aplicação do tratamento termofílico como unidade de pré-tratamento. O presente trabalho investiga o efeito de diferentes mediadores redox na remoção de cor pelo uso de lodo granular anaeróbio sob condiçôes mesofílicas e termofílicas. Adicionalmente, estudou- se em ambas as temperaturas, o efeito de diferentes doadores de elétrons na aceleração dos processos de redução dos corantes. Finalmente, um experimento de fluxo contínuo foi conduzido à $30^{\circ} \mathrm{C}$ e $55^{\circ} \mathrm{C}$, para testar o impacto da temperatura e da contínua dosagem de mediador redox, nas taxas de descoloração.

\section{MATERIAL E MÉTODOS}

\section{Químicos}

Selecionou-se o corante azo RR2 (Reactive Red 2, Procion Red MX-5B) como composto modelo para esse estudo. RR2 foi usado em sua forma analítica, sem adicional purificação. Entretanto, a solução estoque de RR2 era inicialmente hidrolisada, a qual objetivava simular a real forma do corante nas águas residuárias têxteis. A hidrólise consistia no aumento do $\mathrm{pH}$ da solução para $11 \mathrm{com}$ $\mathrm{NaOH}$, seguido por $1 \mathrm{~h}$ de aquecimento à $80^{\circ} \mathrm{C}$, e finalmente na diminuição do $\mathrm{pH}$ para 7 com $\mathrm{HCl}$ (após Beydilli et al, 1998). A Figura 2 traz a forma do corante azo RR2 antes e após a hidrólise.

Selecionou-se como compostos modelos de mediadores redox anthraquinone-2,6-disulfonate (AQDS), anthraquinone-2-sulfonate (AQS) e riboflavina (Vitamina B2), os quais foram usados na sua forma analítica (SigmaAldrich, Gillingham, UK). As estruturas moleculares dos compostos modelos são mostradas na Figura 3.

\section{Experimentos em batelada e de fluxo contínuo}

\section{a) Inóculo e meio basal}

Coletou-se o lodo granular anaeróbio em um reator mesofílico do tipo UASB (upflow anaerobic sludge blanket), o qual tratava águas residuárias de indústrias de papel (Eerbeek, The Netherlands). O lodo mesofílico foi aclimatado por 3 meses à $55^{\circ} \mathrm{C}$ em um reator de leito expandido (EGSB) com
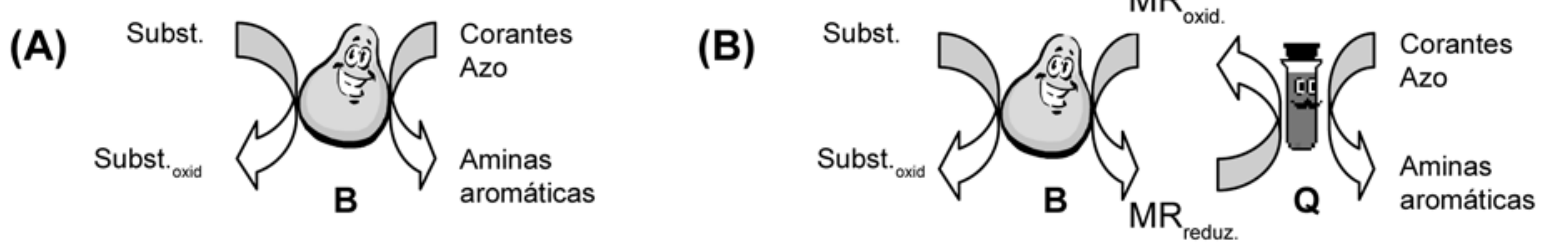

Figura I - Redução anaeróbia de corantes azo por bactéria, na ausência (A) e presença (B) de mediadores redox. As letras $B$ e $Q$ correspondem às reações biológicas e químicas, respectivamente 

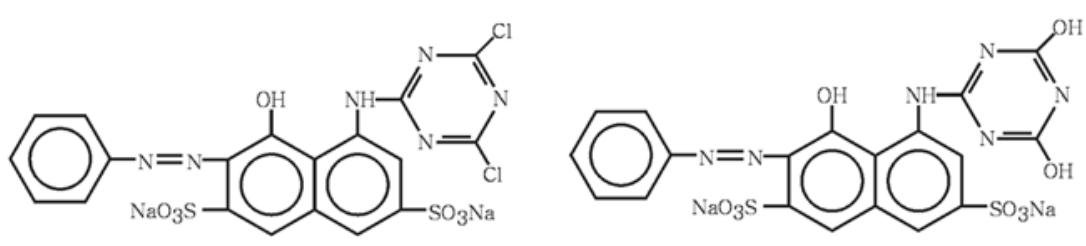

Forma Original (A)

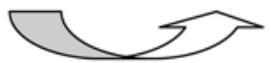

Após Hidrólise (A)

Figura 2 - Estrutura química do corante azo RR2 antes (A) e após (B) hidrólise

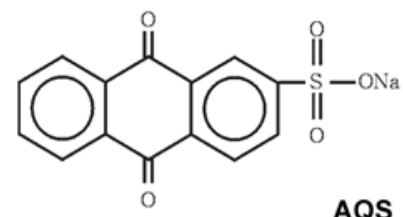<smiles>O=C1c2ccc(S(=O)(=O)O[Na])cc2C(=O)c2ccc(S(=O)(=O)O[Na])cc21</smiles>

Riboflavina

AQS<smiles>Cc1cc2nc3c(=O)[nH]c(=O)nc-3n(CC(O)C(O)C(O)CO)c2cc1C</smiles>

Figura 3 - Estrutura química dos mediadores redox antraquinone-2sulfonate (AQS), antraquinone-2,6-disulfonate (AQDS) e riboflavina, utilizados como compostos modelos

volume útil de 5,6 L. Ele foi operado sob um tempo de detenção hidráulica (TDH) de 6 h e taxa de carga orgânica de 2,5 kg DQO (demanda química de oxigênio) $\mathrm{m}^{-3} \mathrm{~d}^{-1}$. A DQO consistia de uma mistura de glicose e ácidos graxos voláteis (AGV) a uma razão de 1:3. A solução de AGV era neutralizada, a qual continha acetato, propionato e butirato a uma razão de 1:1:1 (também baseada em DQO).

Para os experimentos a $30^{\circ} \mathrm{C}$, o mesmo lodo granular mesofílico foi aclimatado sob as mesmas condições hidráulicas e orgânicas descritas acima, até o alcance de condiçôes de estabilidade operacional.

O meio basal consistia de $(\mathrm{mg} / \mathrm{L})$ : $\mathrm{NH}_{4} \mathrm{Cl}$ (280), $\mathrm{K}_{2} \mathrm{HPO}_{4}$ (250), $\mathrm{MgSO}_{4} \cdot 7 \mathrm{H}_{2} \mathrm{O}(100)$ e $\mathrm{CaCl}_{2} \cdot 2 \mathrm{H}_{2} \mathrm{O}(10)$ e $1 \mathrm{~mL} / \mathrm{L}$ de elementos trácicos, o qual continha (mg/L): $\mathrm{H}_{3} \mathrm{BO}_{3}(50)$, $\mathrm{FeCl}_{2} \cdot 4 \mathrm{H}_{2} \mathrm{O}$ (2000), $\mathrm{ZnCl}_{2}$ (50), $\mathrm{MnCl}_{2} \cdot 4 \mathrm{H}_{2} \mathrm{O}(500), \mathrm{CuCl}_{2} \cdot 2 \mathrm{H}_{2} \mathrm{O}(38)$, $\left(\mathrm{NH}_{4}\right)_{6} \mathrm{Mo}_{7} \mathrm{O}_{24} \cdot 4 \mathrm{H}_{2} \mathrm{O}(50), \mathrm{AlCl}_{3} \cdot 6 \mathrm{H}_{2} \mathrm{O}$ (90), $\mathrm{CoCl}_{2} \cdot 6 \mathrm{H}_{2} \mathrm{O}(2000), \mathrm{NiCl}_{2} \cdot 6 \mathrm{H}_{2} \mathrm{O}$
(92), $\mathrm{Na}_{2} \mathrm{SeO}_{3} \cdot 5 \mathrm{H}_{2} \mathrm{O}$ (162), EDTA (1000) e $\mathrm{HCl} 36 \%$ (1). Resazurina não era incluída na solução de elementos trácicos devido às suas propriedades de mediador redox. $\mathrm{O}$ meio basal era tamponado com 5,0 e 6,2 g/L de bicarbonato de sódio, para as temperaturas de $30^{\circ} \mathrm{Ce} 55^{\circ} \mathrm{C}$, respectivamente, de forma a manter o $\mathrm{pH}$ próximo de 7,1.

\section{b) Testes de atividade}

Para os testes de atividade, $1,3 \pm 0,1 \mathrm{gSSV} / \mathrm{L}$ do lodo previamente aclimatado era adicionado em garrafas em série com volume total de $117 \mathrm{~mL}$, dos quais $50 \mathrm{~mL}$ representavam a fração líquida com meio basal. Selavam-se as garrafas com tampas em borracha do tipo butil, juntamente com prendedores em alumínio. Estabeleciam-se condições anaeróbias nas garrafas através da exaustiva troca do meio gasoso por $\mathrm{N}_{2} / \mathrm{CO}_{2}$ (70\%:30\%) (Manifold Gas System, The Netherlands). Em seguida, $1,5 \mathrm{~g} \mathrm{DQO} / \mathrm{L}$ de doador de elétrons (variável), corante azo RR2 (0,3 mM) e mediadores redox (variável) eram adicionados às garrafas. Controles estéreis eram autoclavados em duas etapas de 240 minutos à $122^{\circ} \mathrm{C}$, com um período de 5 dias de incubaçãa, logo após os diferentes doadores de elétrons, mediadores redox e corante eram adicionados às garrafas a partir de soluçōes estéreis. $\mathrm{O} \mathrm{pH}$ de cada garrafa, assim como a exata quantidade de SSV, eram determinados ao final de cada experimento.

c) Efeito de diferentes mediadores redox na remoção de cor por lodo granular mesofílico e termofílico

Estudou-se sob condiçôes mesofílicas $\left(30^{\circ} \mathrm{C}\right)$ e termofílicas $\left(55^{\circ} \mathrm{C}\right)$ o efeito dos mediadores redox AQDS, AQS e riboflavina na remoção de cor do corante azo RR2 (0,3 mM), na presença de 1,5 g DQO/L do doador de elétrons glicose. Adicionava-se nas diferentes garrafas a mesma concentração de mediadores redox $(0,050 \mathrm{mM})$, onde controles sem adição de mediadores avaliavam o seu efeito catalítico nas taxas de descoloração. Garrafas com lodo autoclavado controlavam a adsorção do corante no lodo além da remoção de cor abiótica por compostos redutivos. Garrafas sem adição de lodo controlavam a estabilidade química do corante nas temperaturas testadas.

d) Efeito de diferentes doadores de elétrons na remoção de cor por lodo granular mesofílico e termofílico

Avaliou-se sob condiçôes mesofílicas $\left(30^{\circ} \mathrm{C}\right)$ e termofílicas $\left(55^{\circ} \mathrm{C}\right)$ o efeito de diferentes doadores de elétrons na redução do corante RR2 $(0,3 \mathrm{mM})$, tanto na presença como na ausência do mediador redox riboflavina $(0,012 \mathrm{mM})$. Os doadores de elétrons acetato, $\mathrm{H}_{2} / \mathrm{CO}_{2}$ e formiato eram testados a uma mesma concentração de $1,5 \mathrm{~g} \mathrm{DQO} / \mathrm{L}$. As garrafas eram incubadas em um agitador rotatório a $50 \mathrm{rpm}$, no escuro. Quando $\mathrm{H}_{2} / \mathrm{CO}_{2}(80 \% / 20 \%)$ era usado como doador de elétrons, o mesmo era adicionado sob uma pressão de 1,8 bars, e a rotação do agitador era aumentada para $200 \mathrm{rpm}$ visando facilitar a transferência de massa do hidrogênio para a fase líquida. Garrafas com lodo autoclavado controlavam a adsorção do corante no lodo além da remoção de cor abiótica por compostos redutivos. Garrafas sem adição de lodo controlavam a estabilidade química do corante nas temperaturas testadas. 
e) Experimento de fluxo contínuo para comprovar o aumento de eficiência de remoção de cor devido ao emprego de mediadores redox

Para comprovar o aumento das taxas de descoloração devido ao emprego de mediadores redox, um curto experimento de fluxo contínuo foi conduzido à $30^{\circ} \mathrm{C}$ e $55^{\circ} \mathrm{C}$. Utilizou-se um reator anaeróbio do tipo EGSB (expanded anaerobic sludge blanket), com volume útil de $0,53 \mathrm{~L}$, concentração da manta de lodo em $30 \mathrm{gSSV} / \mathrm{L}_{\text {reator }}$ e velocidade ascensional de $4 \mathrm{~m} / \mathrm{h}$. Ele era operado com um TDH de 10 h e uma taxa de carga orgânica de of 5,0 kg DQO m $\mathrm{m}^{-3} \mathrm{~d}^{-1}$. A DQO consistia de uma mistura de glicose e ácidos graxos voláteis (AGV) a uma razão de 1:3. Os reatores mesofílicos eram denominados R1 e R2, e os termofílicos R3 e R4. Avaliou-se o efeito catalítico do mediador redox AQDS, através da sua dosagem contínua $(0,025 \mathrm{mM})$ nos reatores R2 e R4. A mesma concentração de corante RR2 (0,60 g/L) foi utilizada nos quatro reatores, fornecendo uma taxa de carga de $1,25 \mathrm{gRR}_{2} \mathrm{~L}^{-1} \mathrm{~d}^{-1}$. O meio basal utilizado é o mesmo descrito para os experimentos em batelada.

\section{Análises}

A remoção de cor do composto modelo RR2 foi determinada fotometricamente (Spectronics 60, Milton-Roy Analytical Products Division, Belgium), cuja absorbância era lida em 539 nm, ou seja, no máximo comprimento de onda do RR2. Usou-se um coeficiente de extinção de $33,3 \mathrm{UA} \mathrm{cm}^{-1} \mathrm{mM}^{-1}$ para a conversão dos valores de absorbância em valores de concentração. As amostras eram centrifugadas por 3 minutos a uma velocidade de $10000 \mathrm{rpm}$ antes de se efetuar a leitura. A Produção de metano era monitorada pela injeção de um volume de $100 \mathrm{~mL}$ em um cromatógrafo de gás modelo 438/S (Packard-Becker, Delft, The Netherlands), equipado com uma coluna em aço $(2 \mathrm{~m} \times 2 \mathrm{~mm})$ contendo Porapak Q (80/100 mesh, Milipore Corp., Bedford, M.A.). As temperaturas da coluna, porta de injeção e detector de ionização de chamas eram $60^{\circ} \mathrm{C}, 200^{\circ} \mathrm{C}$ e $220^{\circ} \mathrm{C}$, respectivamente, com nitrogênio sendo o transportador de gases (20 mL/min). Ácidos Graxos Voláteis, metanol e etanol, eram medidos em um croma-tógrafo de gás modelo Hewlett Packard 5890 (Palo Alto, USA), equipado com uma coluna em vidro (2 $\mathrm{m} \times 2 \mathrm{~mm})$ contendo Supelcoport (100-120 mesh), a qual era coberta com 10\% Fluorad FC 431. As temperaturas da coluna, porta de injeção e detector de ionização de chamas eram $130^{\circ} \mathrm{C}, 200^{\circ} \mathrm{C}$ e $280^{\circ} \mathrm{C}$, respectivamente. Para os álcoois, a temperatura da coluna era ajustada para $70^{\circ} \mathrm{C}$. Sucrose, frutose, glicose, lactato e formiato eram medidos em um cromatógrafo líquido (HPLC) equipado com uma coluna do tipo Ion-300 e detector de índice refrativo de acordo com Van Lier et al (1997). Sólidos Suspensos Voláteis (SSV) eram analisados de acordo com o $A P H A$ Standard Methods (1998).

\section{RESULTADOS E DISCUSSÃO}

\section{Efeito de diferentes mediadores redox na remocão de cor por lodo granular mesofílico e termofílico}

Uma cinética de primeira-ordem com relação à concentração de RR2 foi utilizada para calcular os valores da constante de primeira-ordem " $k$ ", seguindo a equação 1 mostrada abaixo:

$A_{t}=A_{0} e^{-k t}$

$A_{t}$ é a absorbância no tempo " $\mathrm{t}$ ", $\mathrm{A}_{0}$ é a absorbância no tempo $t=0$, " $k$ " é a constante de primeira-ordem $\left(\mathrm{dia}^{-1}\right) \mathrm{e}$ " $\mathrm{t}$ " é o tempo acumulado do experimento (dias). O tempo era plotado contra $\ln \left(\mathrm{A}_{\mathrm{t}} / \mathrm{A}_{0}\right)$ e o valor de k era estimado pelo coeficiente angular da regressão linear.

$\mathrm{Na}$ presença de glicose como doador de elétrons, uma completa remoção de cor por lodo granular mesofílico e termofílico foi encontrada em todos os casos (Tabela 1). A adição de glicose aumentou as taxas de redução do corante $\mathrm{RR} 2$ em 2,2 vezes $\left(30^{\circ} \mathrm{C}\right)$ e 2,7 vezes $\left(55^{\circ} \mathrm{C}\right)$, quando comparado com os respectivos controles endógenos (sem adição de glicose). Adicionalmente, pode-se observar o efeito evidente de concentraçōes catalíticas dos mediadores redox na velocidade de descoloração. Por exemplo, comparando-se as taxas de redução de RR2 obtidas com riboflavina com os valores obtidos sem a adição de qualquer mediador redox, há um aumento de cerca de 19,9 vezes à $30^{\circ} \mathrm{C}$, e 5,2 vezes à $55^{\circ} \mathrm{C}$ (Tabela 1). Os outros mediadores redox AQS e AQDS foram também eficientes na redução de RR2, mas abaixo das propriedades catalíticas da riboflavina. A distinta capacidade da riboflavina em acelerar a redução do corante RR2 foi também verificada em Dos Santos et al (2004). Entretanto AQS teve propriedades mediadoras superiores às da riboflavina com os outros tipos de corantes azo testados e, portanto, diferentes estruturas moleculares. Em conclusão, as interações eletroquímicas entre mediadores redox e corantes, as quais são dependentes de fatores como os tipos e concentrações dos corantes e mediadores redox, temperatura, $\mathrm{pH}$, doador de elétrons e etc., é que irão determinar a cinética da reação (Dos Santos, 2005). Tais observaçôes estão de acordo com as conclusões de Moir et al (2001), durante o estudo da relação estrutura-atividade na redução de corantes azo por Clostridium paraputrificum.

Observou-se também o claro efeito da temperatura na descoloração de RR2 (Tabela 1). Por exemplo na ausência de mediadores redox, a cinética da reação era aumentada em 3,7 vezes à $55^{\circ} \mathrm{C}$ comparada à $30^{\circ} \mathrm{C}$. $\mathrm{Na}$ presença de $\mathrm{AQS}$ e AQDS sob condiçôes termofílicas, os valores de k eram aumentados em 4,5 e 2,9 vezes, respectivamente. Rau et al (2002) também encontraram que o mediador redox AQS era mais efetivo to que AQDS na redução do corante Amarant pela cultura pura de Sphingomonas xenophaga $\mathrm{BN} 6$. Os últimos autores atribuíram tal observação ao valor mais negativo do potencial redox padrão $\left(\mathrm{E}_{0}\right.$ ') do AQS $(-225 \mathrm{mV})$ comparado com AQDS $(-184 \mathrm{mV})$, o que refletia uma melhor capacidade de transferência de elétrons da sua forma reduzida para os corantes. Interessantemente com riboflavina, valores próximos de $\mathrm{k}$ foram encontrados em ambas as temperaturas testadas (Tabela 1), o que provavelmente foi devido a saturações cinéticas resultante de uma alta afinidade dos inóculos utilizados por riboflavina, diminuindo assim o impacto da temperatura nas taxas de remoção de cor. Field e Brady (2003) observaram uma alta afinidade de lodo granular por riboflavina, durante a redução do corante azo Mordant Yellow 10 sob condiçôes mesofílicas, a qual foi assumida como cinética de ordem-zero.

\section{Efeito de diferentes doadores de elétrons na remoção de cor por lodo granular mesofílico e termofílico}

Pode-se consideravelmente acelerar a cinética de remoção de cor por lodo gra- 
nular, através do uso de diferentes doadores de elétrons (Tabela 2). Constatouse que hidrogênio era um excelente doador de elétrons (Figura 4B), aumentando as taxas de redução de RR2 em até 10,5 vezes à $55^{\circ} \mathrm{C}$ e 7,6 vezes à $30^{\circ} \mathrm{C}$, comparados com garrafas contendo glicose (Tabela 2). Acetato, apesar de ser um bom substrato para metanogênese, se mostrou um pobre doador de elétrons para a redução do corante RR2 (Tabela 2, Figura 4A). Durante o estudo de diferentes doadores de elétrons na redução do tetracloreto de carbono $\left(\mathrm{CCl}_{4}\right)$, o qual possui um mecanismo de redução semelhante às do corante azo, hidrogênio foi também um efetivo doador de elétrons, onde acetato, metanol e glicose tiveram uma baixa capacidade de doação (Cervantes et al, 2004). No mesmo estudo, 0,020 $\mathrm{mM}$ do mediador redox AQDS aumentou de forma marcante as taxas de redução de $\mathrm{CCl}_{4}$, fazendo com que mesmo os pobres doadores de elétrons fossem efetivos na desclorinação. A verdadeira razão bioquímica para a baixa cinética de remoção de cor das arqueas metanogênicas na presença acetato é ainda desconhecida. Porém, muito provavelmente deve ser relacionada com a competição entre metanogênese e a redução dos corantes, pelos equivalentes reduzidos gerados na conversão do doador de elétrons. Por exemplo na metanogênese a partir do acetato, as enzimas envolvidas não utilizam $\mathrm{NAD}^{+}$ou $\mathrm{NADP}^{+}$como coenzimas, e sim uma coenzima do tipo 5-dezaflavin $\mathrm{F}_{420}$ (Berk e Thauer, 1997). É presentemente aceito que NADH ou $\mathrm{NAD}(\mathrm{P}) \mathrm{H}$ são os doadores de elétrons primários na redução biológica de corantes azo (Stolz, 2001; Blumel e Stolz, 2003).

Foi novamente constatado com os doadores de elétrons testados, um considerável aumento nos valores de $\mathrm{k}$ nas incubações à $55^{\circ} \mathrm{C}$ comparados aos valores à $30^{\circ} \mathrm{C}$. Ademais, o mediador redox riboflavina acelerou a descoloração redutiva em todos os casos, mostrando assim a habilidade das hidrogenotróficas e acetoclásticas metanogênicas, em utilizarem riboflavina como aceptor de elétrons (Tabela 2). Por exemplo nas garrafas contendo hidrogênio e riboflavina, a redução de RR2 era acelerada em 4,6 e 3,8 vezes, para incubaçôes à $30^{\circ} \mathrm{C} \mathrm{e}$ $55^{\circ} \mathrm{C}$, respectivamente, quando comparados com as garrafas contendo apenas hidrogênio.
Tabela I - Efeito de diferentes mediadores redox nas taxas de remoção de cor do corante azo RR2 por lodo granular mesofilico e termofílico na presença de glicose como doador de elétrons ( I ,5 g DQO/L). O desvio padrão é mostrado em parêntesis, em que os valores de $\mathrm{k}$ foram calculados a partir de triplicatas

\begin{tabular}{cccc}
\hline $\begin{array}{c}\text { Doador } \\
\text { de Elétrons }\end{array}$ & $\begin{array}{c}\text { Mediador redox } \\
(0,050 \mathrm{mM})\end{array}$ & $\begin{array}{c}\mathrm{k} / \mathrm{SSV}\left(\mathrm{dia}^{-1} \mathrm{~g} \mathrm{SSV}^{-1} \mathrm{~L}\right) \\
30^{\circ} \mathrm{C}\end{array}$ & $55^{\circ} \mathrm{C}$ \\
\hline \multirow{3}{*}{ Glicose } & Nenhum & $0,23(0,05)$ & $0,84(0,02)$ \\
& AQS & $0,51(0,04)$ & $2,30(0,04)$ \\
& AQDS & $0,40(0,04)$ & $1,15(0,04)$ \\
& Riboflavina & $4,58(0,59)$ & $4,40(0,35)$ \\
\hline
\end{tabular}

Tabela 2 - Redução do corante azo RR2 por lodo granular mesofilico e termofilico na presença de diferentes doadores de elétrons, e efeito do mediador redox riboflavina nas taxas de remoção de cor. O desvio padrão é mostrado em parêntesis, em que os valores de k foram calculados a partir de triplicatas e assumindo uma reação de primeira-ordem

\begin{tabular}{cccc}
\hline $\begin{array}{c}\text { Doador de } \\
\text { Elétrons }\end{array}$ & $\begin{array}{c}\text { Presença ou não de } \\
\text { Riboflavina }(0,012 \mathrm{mM})\end{array}$ & \multicolumn{2}{c}{$\mathrm{k} / \mathrm{SSV}\left(\mathrm{dia}^{-1} \mathrm{~g} \mathrm{SSV}^{-1} \mathrm{~L}\right)$} \\
& - & $0,23(0,05)$ & $0,84(0,02)$ \\
Glicose & + & $0,56(0,01)$ & $1,43(0,05)$ \\
& - & $0,12(0,01)$ & $1,08(0,08)$ \\
\multirow{2}{*}{ Acetato } & + & $0,44(0,02)$ & $1,66(0,09)$ \\
& - & $0,93(0,03)$ & $3,99(0,05)$ \\
$\mathrm{H}_{2} / \mathrm{CO}_{2}$ & + & $4,28(0,19)$ & $15,02(1,08)$ \\
& - & $0,71(0,09)$ & $1,59(0,14)$ \\
Formiato & + & $1,46(0,11)$ & $3,11(0,10)$ \\
\hline
\end{tabular}

A

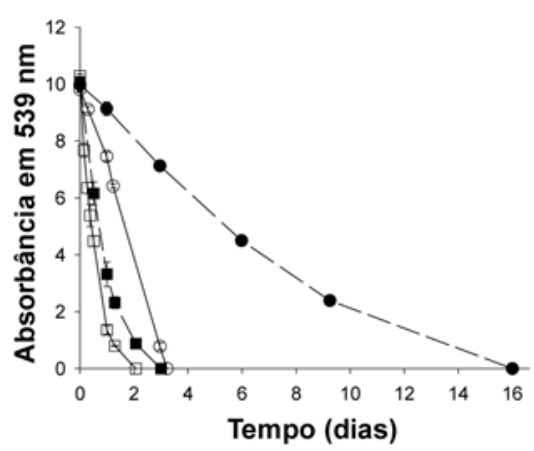

B

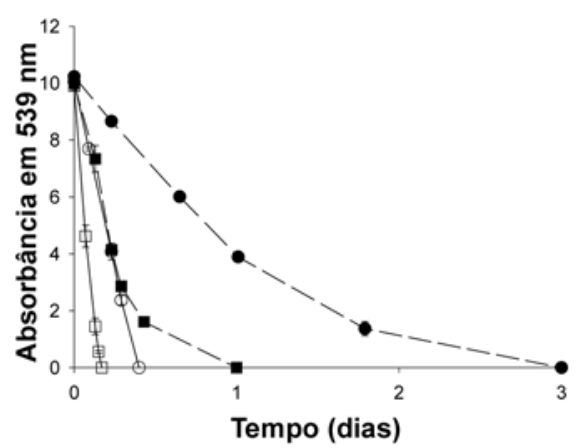

Figura 4 - Redução do corante azo RR2 por lodo granular mesofílico e termofílico na presença dos doadores de elétrons (DE) acetato (A) e $\mathrm{H}_{2} / \mathrm{CO}_{2}$ (B). Os símbolos apresentados nos gráficos representam: DE à $30^{\circ} \mathrm{C}\left({ }^{\circ}\right), \mathrm{DE}+$ riboflavina à $30^{\circ} \mathrm{C}(\mathrm{O}), \mathrm{DE}$ à $55^{\circ} \mathrm{C}(\square), D E$ + riboflavina à $55^{\circ} \mathrm{C}(\square)$. As concentrações dos doadores de elétrons e do mediador redox riboflavina eram I,5 g DQO/L e 0,0 I 2 mM, respectivamente. Garrafas sem adição de lodo controlavam a estabilidade química do corante 
Experimento de fluxo contínuo para comprovar o aumento de eficiência de remoção de cor devido ao emprego de mediadores redox

Operaram-se inicialmente os reatores mesofílicos e termofílicos por um período de 35 dias, sem qualquer contato com o corante RR2 e o mediador redox AQDS (Figura 5). Após a obtenção de condiçôes estáveis de operação, com eficiências de remoção de $\mathrm{DQO}$ em torno de $85 \%$, os compostos RR2 e AQDS foram introduzidos no sistema. Pode-se comprovar através do experimento de flu- xo contínuo que a remoção de cor foi quase que imediata em todos os reatores, o que indicou um processo co-metabólico. Observou-se também uma adsorção inicial do corante à manta de lodo, mas que certamente não foi a principal razão da remoção inicial de cor dos reatores. Pode-se verificar também a excelente performance dos reatores termofílicos R3 e R4, comparados com os reatores mesofílicos R1 e R2 (Figura 5).

Além do mais, pode-se observar que o impacto do mediador redox AQDS era significantemente reduzido à $55^{\circ} \mathrm{C}$, ao passo que um visível efeito era observado nos reatores mesofílicos (Figura 5). Obteve-se um valor médio

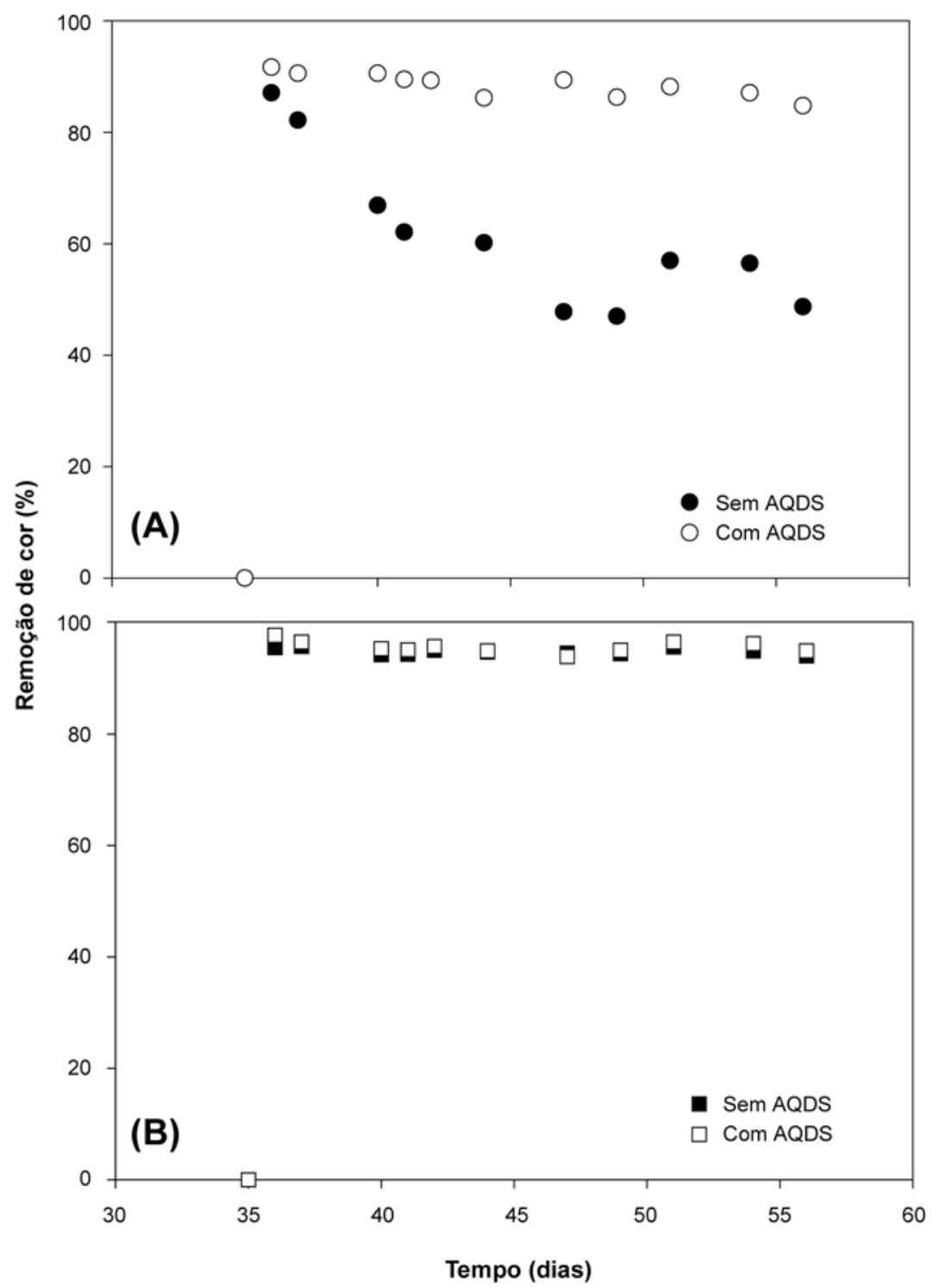

Figura 5 - Desempenho dos reatores mesofílicos $R I$ e $R \mathbf{2}(A)$, e reatores termofílicos $R 3$ e R4 (B), em termos de eficiência de remoção de cor. Os reatores $R 2$ e $R 4$ foram dosados com $0,025 \mathrm{mM}$ do mediador redox AQDS de eficiência de remoção de cor em torno de $95 \%$ para os reatores termofílicos R3 e R4, e um valor médio de $56 \%$ e $88 \%$ para os reatores mesofílicos R1 (sem AQDS) e R2 (com AQDS), respectivamente. Assim, devido ao efeito da temperatura nas taxas de descoloração, o efeito catalítico do mediador redox era diminuído sob condiçôes termofílicas. $\mathrm{O}$ efeito evidente do mediador redox AQDS à $30^{\circ} \mathrm{C}$ está em acordo com as observaçôes de Cervantes et al (2001), durante a remoção do corante azo Acid Orange 7 em um reator UASB. Quando AQDS não era suplementado, os valores de eficiência eram cerca de $86 \%$, se aumentado para aproximadamente $99 \%$, quando uma concentração de 0,030 mM de AQDS era introduzida no sistema. Dos Santos et al (2003) também verificaram uma alta estabilidade e altos valores de eficiência de remoção de cor na utilização de tratamento termofílico, o que está de acordo com as observaçôes da presente investigação.

Todos os reatores apresentaram capacidade similar de remoção de DQO (> 90\%), em termos dos doadores de elétrons glicose e AGV, em que somente baixíssimas concentrações de AGV foram detectadas no efluente. Os produtos da oxidação da glicose, por exemplo piruvato, formiato, lactato e álcoois, nunca se mostraram presentes no efluente. Assim sendo, a taxa de formação de elétrons era similar entre os quatro reatores operados. Logo, o melhor desempenho dos reatores termofílicos era atribuído ao efeito da temperatura na capacidade de transferência de elétrons, resultando em um aumento considerável das taxas de remoção de cor encontradas.

\section{CONCLUSÕES}

Comprovou-se o impacto marcante dos mediadores redox nos processos de descoloração, aumento a cinética da reação em até 1 ordem de magnitude. Comparado com tratamento mesofílico, remoções sob condições termofílicas eram extremamente aceleradas, o que traz boas perspectivas ao mesmo na sua inclusão como uma unidade de pré-tratamento das águas residuárias de indústrias têxteis. Hidrogênio se mostrou extremamente efetivo como doador de elétrons para o processo de descoloração redutiva de corantes azo quando comparado com glicose, formiato e acetato. Pode-se observar que o impacto dos mediadores redox nas taxas de descoloração sob con- 
diçōes termofílicas era consideravelmente diminuído, o qual pode representar uma grande economia durante a contínua dosagem desses químicos nas estações de tratamento de esgotos.

\section{AGRADECIMENTOS}

$\mathrm{O}$ autor é grato ao $\mathrm{CNPq}$ - Conselho Nacional de Desenvolvimento Científico e Tecnológico pela concessão da bolsa de doutorado no exterior (Processo número 200488/01-5).

\section{REFERÊNCIAS}

APHA. Standard methods for the examination of water and wastewater. Washington D.C. American Public Health Association. 1998.

BERK, H. e THAUER, R. K. Function of coenzyme F420-dependent NADP reductase in methanogenic archaea containing and NADPdependent alcohol dehydrogenase. Archives of Microbiology, v.168, p.396-402. 1997

BEYDILLI, M. I., PAVLOSTATHIS, S. G. e TINCHER, W. C. Decolorization and toxicity screening of selected reactive azo dyes under methanogenic conditions. Water Science and Technology, v.38, n.4-5, p.225-232. 1998.

BLUMEL, S. e STOLZ, A. Cloning and characterization of the gene coding for the aerobic azoreductase from Pigmentiphaga kullae k24. Applied Microbiology and Biotechnology, v.62, p.186-190. 2003.

CERVANTES, F. J. et al. Enhanced decolourisation of Acid Orange 7 in a continuous UASB reactor with quinones as redox mediators. Water Science and Technology, v.44, n.4, p.123-128. 2001.

CERVANTES, F. J. et al. Quinone-respiration improves dechlorination of carbon tetrachloride by anaerobic sludge. Applied Microbiology and Biotechnology, v.64, p.702-711. 2004.

CHRISTIE, R. Colour Chemistry. Cambridge, United Kingdom: The Royal Society of Chemistry. 2001.

DOS SANTOS, A. B. et al. Effect of redox mediator, AQDS, on the decolourisation of a reactive azo dye containing triazine group in a thermophilic anaerobic EGSB reactor. Enzyme and Microbial Technology, v.33, n.7, p.942951. 2003.

DOS SANTOS, A. B. et al. Effect of different redox mediators during thermophilic azo dye reduction by anaerobic granular sludge and comparative study between mesophilic $\left(30^{\circ} \mathrm{C}\right)$ and thermophilic $\left(55^{\circ} \mathrm{C}\right)$ treatments for decolourisation of textile wastewaters. Chemosphere, v.55, p.1149-1157. 2004

DOS SANTOS, A.B. Reductive Decolourisation of Dyes by Thermophilic Anaerobic Granular Sludge, PhD-Thesis, Wageningen University, Wageningen, The Netherlands, 176 p. 2005.

DOS SANTOS, A. B. et al. Enhancing the electron transfer capacity and subsequent colour removal in bioreactors by applying thermophilic anaerobic treatment and redox mediators.
Biotechnology and Bioengineering, v. 89, n.1, p. 42-52. .2005.

DURAN, N., ROSA et al. Applications of laccases and tyrosinases (phenoloxidases) immobilized on different supports: A review. Enzyme and Microbial Technology, v.31, n.7, p.907-931. 2002.

FIELD, J. A. e BRADY, J. Riboflavin as a redox mediator accelerating the reduction of the azo dye Mordant Yellow 10 by anaerobic granular sludge. Water Science and Technology, v.48, n.6, p.187-193. 2003.

HEINFLING, A., BERGBAUER, M. e SZEWZYK, U. Biodegradation of azo and phthalocyanine dyes by Trametes versicolor and Bjerkandera adusta. Applied Microbiology and Biotechnology, v.48, n.2, p.261-66. 1997.

KECK, A. et al. Reduction of azo dyes by redox mediators originating in the naphthalenesulfonic acid degradation pathway of Sphingomonas sp. strain BN6. Applied and Environmental Microbiology, v.63, n.9, p.3684-3690. 1997.

LOVLEY, D. R. et al. Humic substances as electron acceptors for microbial respiration. Nature, v.382, p.445-448. 1996.

MOIR, D., MASSON, S. e CHU, I. Structureactivity relationship study on the bioreduction of azo dyes by Clostridium paraputrificum. Environmental Toxicology and Chemistry, v.20, n.3, p.479-484. 2001.

RAU, J., KNACKMUSS, H. J. e STOLZ, A. Effects of different quinoid redox mediators on the anaerobic reduction of azo dyes by bacteria. Environmental Science and Technology, v.36, p.1497-1504. 2002.

STOLZ, A. Basic and applied aspects in the microbial degradation of azo dyes. Applied Microbiology and Biotechnology, v.56, p.6980. 2001 .
VAN DER ZEE, F. P. et al. Application of redox mediators to accelerate the transformation of reactive azo dyes in anaerobic bioreactors. Biotechnology and Bioengineering, v.75, n.6, p.691-701. 2001.

VAN LIER, J. B. et al. Anaerobic treatment of partly acidified wastewater in a two-stage expanded granular sludge bed (EGSB) system at $8^{\circ} \mathrm{C}$. Water Science and Technology, v.36, n.67, Sept.-Oct., 1997, p.317-324. 1997.

WEISBURGER, J. H. Comments on the history and importance of aromatic and heterocyclic amines in public health. Mutation Research, v.506-507, p.9-20. 2002.

ZIMMERMANN, T., KULLA, H. e LEISINGER, T. Properties of purified Orange II azo reductase, the enzyme initiating azo dye degradation by Pseudomonas KF46. European Journal of Biochemistry, v.129, p.197-203. 1982.

ZOLLINGER, H. Color chemistry - Syntheses, properties and applications of organic dyes pigments. New York, NY: VCH. 83-148 p. 1987.

\section{Endereço para correspondência:}

\author{
André B. dos Santos \\ Universidade Federal do Ceará \\ Campus do Pici, bloco 7 I 3 \\ Departamento de Engenharia \\ Hidráulica e Ambiental \\ 60455-760 \\ Fortaleza - Ceará - Brasil \\ Telefone: (085) 40089624 \\ E-mail: andrebds@deha.ufc.br
}

